\title{
Synthesis and Characterization of Undoped and Magnesium Doped Zinc Oxide Nanoparticles
}

\author{
Roxy M S ${ }^{* 1}$, Ananthu $\mathrm{A}^{1}$, Sumithranand V B ${ }^{2}$ \\ ${ }^{1}$ Nanoscience Research Laboratory, Research and Post Graduate Department of Physics (Affiliated Research \\ Center of University of Kerala), Sree Narayana College, Kollam, Kerala, India \\ ${ }^{2}$ Department of Physics, Government Polytechnic College, Ezhukone, Kollam, Kerala, India
}

\begin{abstract}
Article Info

Volume 8 Issue 2

Page Number: 134-139

Publication Issue :

March-April-2021

\section{Article History}

Accepted : 20 March 2021

Published : 29 March 2021

Undoped and $\mathrm{Mg}$-doped $\mathrm{ZnO}$ nanoparticles were synthesized by co-precipitation method. The synthesized nanoparticles are successfully characterized by XRD, SEM, and UV-visible analysis. The Structure, Morphology, and Optical activity of the synthesized nanoparticle were studied with respect to $\mathrm{ZnxMg}_{1-\mathrm{x}} \mathrm{O}$ (where $\mathrm{x}=0$, $2.5 \% \mathrm{M}$ and $7.5 \% \mathrm{M}$ ). The XRD patterns revealed the wurtzite structure for all the nano samples. XRD studies confirmed that the crystalline size increased with increase in $\mathrm{Mg}$ content. The surface morphology of the prepared pure and $\mathrm{Mg}$ doped $\mathrm{ZnO}$ nanoparticles are investigated by SEM analysis. Optical characterization reveals that band gap energy decreases from 3.24 to $3.13 \mathrm{eV}$ with $\mathrm{Mg}$ doping. UV-Visible results revealed that absorption underwent a red shift with $\mathrm{Mg}$ into $\mathrm{ZnO}$ as compared to pure $\mathrm{ZnO}$.

Keywords: $\mathrm{ZnO}$ nano particles, Co-precipitation, Nano particles, UV-Visible analysis
\end{abstract}

\section{INTRODUCTION}

Among nanomaterials, $\mathrm{ZnO}$ is the most noteworthy metal oxides to the extent that its application perceptions are concerned. So, their synthesis procedures and the rules governing their combination are also important. The various parameters used play an authoritative function in the progress of different types of fabrication procedures. A large number of varied methods were reported globally for the synthesis of $\mathrm{ZnO}$ nano-powder, nano-composites, nanofilms, etc., These varied methods up to some extent either evolved or pre-decided to give some sort of useful applications viz. photo-catalytic activities of different dyes, drugs, pesticides, etc., anti-microbial activities against harmful bacteria, protozoans, etc., polymer nanocomposites with characteristic optical, mechanical behaviors, etc.; growth on different substrates like thin films finds their uses in devices, solar cells, sensors, electronics/ photonics, semiconductors, etc. in anti-oxidant studies and so on $[1,2]$. Zinc is an essential element whose significance to health is increasingly appreciated[3].

Recent literature reported that $\mathrm{Mg}$ doping in nanoparticles was found to be a good method for tuning of band gap and photoluminescence of $\mathrm{ZnO}$ nanoparticles[4, 5]. Magnesium doping of $\mathrm{ZnO}$ can be achieved in several ways including sol-gel, solid-state doping, calcination at different temperatures, vapor 
phase transport and pulsed laser deposition [6,7-10]. In this work, we have synthesized undoped and $\mathrm{Mg}$ doped $\mathrm{ZnO}$ nanoparticles by co-precipitation method. Structural, morphological and optical properties of the prepared nanoparticles have been studied in detail.

\section{METHODS AND MATERIAL}

\subsection{Preparation of pure $\mathrm{ZnO}$ nanoparticles}

The zinc oxide nanoparticles were prepared by coprecipitation method using zinc chloride and sodium hydroxide as precursors. Zinc chloride of equivalent weight $34.0715 \mathrm{~g}(1 \mathrm{M})$ was added in water. Then the solution was kept under constant stirring for 30 minutes using magnetic stirrer to completely dissolve the zinc chloride. $1 \mathrm{M}, 250 \mathrm{ml}$ Sodium hydroxide solution is prepared. After the complete dissolution of Zinc chloride, $1 \mathrm{M}$ of sodium hydroxide solution was added under constant stirring, drop by drop touching the walls of the vessel. The reaction was allowed to proceed under constant stirring for 5 hours after the complete addition of sodium hydroxide. The solution was allowed to settle down and the supernatant solution was then discarded carefully. The remaining solution was centrifuged at $5000 \mathrm{rpm}$ for 10 minutes and the supernatant was discarded. The obtained nanoparticles were washed using distilled water and acetone for many times. After washing, the nanoparticles were dried at $100^{\circ} \mathrm{C}$ for 6 hours. The nanoparticle is taken out and grind into powder. After grinding the particles, the powder is calcined at $400^{\circ} \mathrm{C}$ for 4 hours. During calcination the complete conversion of zinc hydroxide into zinc oxide takes place.

\subsection{Preparation of $\mathrm{Mg}$ dopped $\mathrm{ZnO}$ nanoparticles}

$\mathrm{Mg}$ doped zinc oxide nanoparticles were prepared by co precipitation method using zinc chloride, anhydrous $\mathrm{MgCl}_{2}$ and sodium hydroxide as precursors. Here $0.1 \mathrm{M}, 300 \mathrm{ml}$ zinc chloride solution is prepared and is stirred for 30 minutes. To it $2.5 \% \mathrm{Mg}$ is doped such that the solution contains $292.5 \mathrm{ml}$ of $\mathrm{ZnCl}_{2}$ and $7.5 \mathrm{ml}$ of $\mathrm{Mg}$. This solution is again stirred for 30 minutes. After stirring, $0.1 \mathrm{M} 150 \mathrm{ml}$ of $\mathrm{NaOH}$ is added drop by drop through the walls of the beaker. The solution mixture is stirred for 5 hours at room temperature. The precipitate is centrifuged and washed in distilled water and acetone for several times. Then the samples are dried at $100^{\circ} \mathrm{C}$ for 6 hours. The nanoparticle is taken out and grind into powder. After grinding the particles, the powder is calcined at $400^{\circ} \mathrm{C}$ for 4 hours. To synthesize 7.5\% Mg-doped $\mathrm{ZnO}$, molar ratios of $\mathrm{ZnCl}_{2}$ and $\mathrm{MgCl}_{2}$ were measured as $\mathrm{Zn}_{1-\mathrm{x}} \mathrm{Mg}_{\mathrm{x}} \mathrm{O}$ (where $\mathrm{x}=0.075$ ) and the above procedure is repeated.

\section{III.RESULTS AND DISCUSSION}

\subsection{Powder XRD analysis of $\mathrm{ZnO}$ nanoparticles}

Fig.1 illustrates the X-ray diffraction (XRD) patterns for the pure $\mathrm{ZnO}$ samples. The $\mathrm{X}$-ray powder diffraction patterns of the $\mathrm{ZnO}$ nanoparticles were recorded using $\mathrm{X}$-ray Diffractometer equipped with nickel filtered $\mathrm{Cu}-\mathrm{K} \alpha 1$ radiation $\left(\lambda=1.5406 \mathrm{~A}^{\circ}\right)$. The data have been collected in the scan range $(2 \theta)$ from $20-80^{\circ}$. In the figure, major peaks are seen at XRD spectra show peaks at $(2 \theta)$ positions $31.750,34.450$, 36.20, 47.50, 56.550, 62.80, 66.30, 67.900, 69.10, 72.40, and 76.850 which can be consigned to diffraction from (100), (002), (101), (102), (110), (103), (200), (112), (201), (004) and (202) planes respectively. The $\mathrm{XRD}$ pattern shows the presence of the hexagonal wurtzite phase crystal structure for pure $\mathrm{ZnO}$ nanoparticles. 


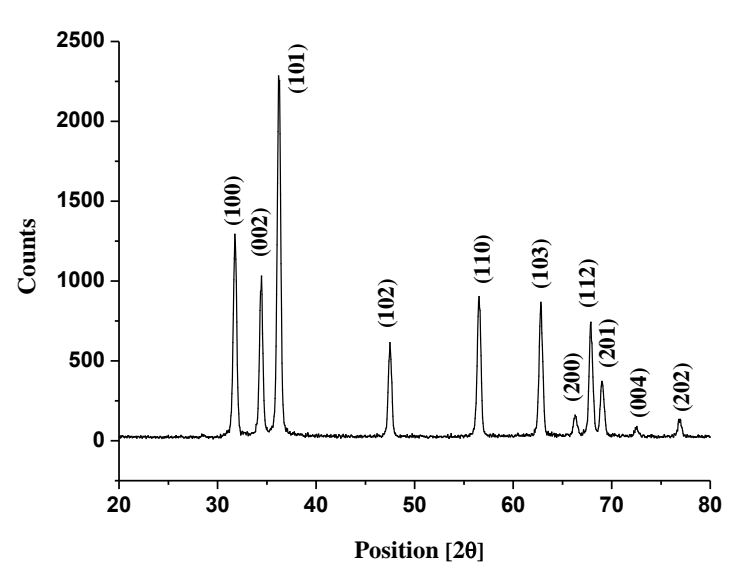

Figure 1: The powder $\mathrm{X}$-ray diffraction pattern $(\mathrm{XRD})$ patterns of the synthesized $\mathrm{ZnO}$ NPs

The mean crystallite size is obtained as $16.3821 \mathrm{~nm}$ by using Scherrer formula (5)

$$
D=\frac{0.9 \lambda}{\beta \cos \theta}
$$

where, $D$ is average crystallite size, $\lambda$ is wavelength of incident beam (1.5406 A0), $\beta$ is full width at halfmaximum (FWHM) in radians and $\theta$ is scattering angle in degrees. The FWHM values were estimated using Microcal Origin Version 8.5.

For a wurtzite phase, the lattice parameters are calculated by using the Eq. (6-8) where, a = b, and c are the lattice parameters, dhkl is the interplanar distance corresponding to its Miller indices (hkl).

$$
\begin{gathered}
\frac{1}{d_{h b l}^{2}}=\frac{4}{3}\left\lceil\frac{h^{2}+k^{2}+h k}{a^{2}}\right\rceil+\frac{l^{2}}{c^{2}} \\
a=\frac{1}{\sqrt{3}} \frac{\lambda}{\operatorname{sine}(100)} \\
c=\frac{\lambda}{\sin \theta(002)}
\end{gathered}
$$

The calculated lattice constants $(\mathrm{a}=3.2521 \AA$ and $\mathrm{c}=$ $5.2028 \AA$ ) also indicate the hexagonal structure of $\mathrm{ZnO}$. The standard value of the c/a ratio for the wurtzite structure is about 1.63. There is a good agreement between obtained value 1.5998 , and the standard one.

\subsection{Powder $\mathrm{XRD}$ analysis of $\mathrm{Mg}$ doped $\mathrm{ZnO}$ nanoparticles}

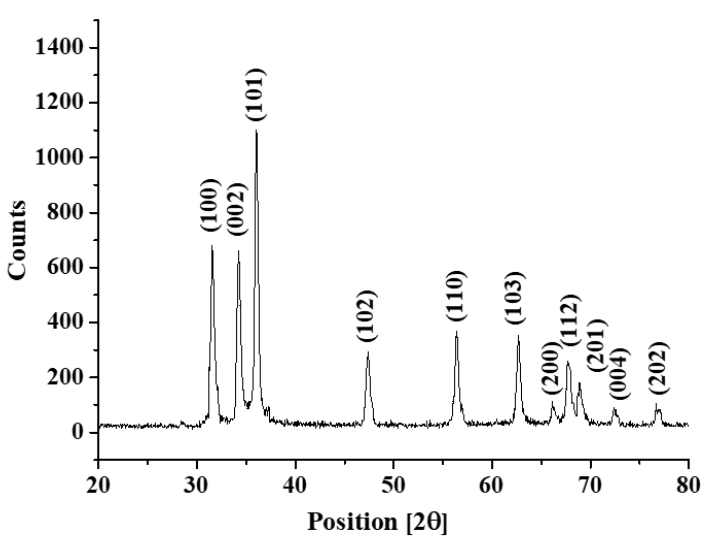

Figure 2: (a) The powder X-ray diffraction pattern (XRD) patterns of the synthesized $\mathrm{Mg}$ doped $\mathrm{ZnO}$ $\left(\mathrm{Mg}_{\mathrm{x}} \mathrm{Zn}_{1-\mathrm{x}} \mathrm{O}\right.$, where $\left.\mathrm{x}=0.025 \%\right)$ nanoparticles

The pattern of $\mathrm{Mg}$ doped $\mathrm{ZnO}\left(\mathrm{Mg}_{\mathrm{x}} \mathrm{Zn}_{1-\mathrm{x}} \mathrm{O}\right.$, where $\mathrm{x}=$ $0.025 \%$ ) nanoparticles has been revealed that no secondary phases are formed with $\mathrm{Mg}$ dopant into $\mathrm{ZnO}$ crystal lattice and no significant changes are observed in the XRD pattern of the $\mathrm{Mg}$-doped $\mathrm{ZnO}$ nanoparticles. The intensity of the XRD peak is found to be decreases with increase in $\mathrm{Mg}$ doping concentration (Fig.2 a and b). The calculated average crystalline sizes using Debye Scherer formula are $24.91 \mathrm{~nm}$ and $38.28 \mathrm{~nm}$ for the concentrations 0.025 and $0.075 \%$ of $\mathrm{Mg}$ doped $\mathrm{ZnO}$. From the calculated values, it is observed that the mean crystallite size increases with an increase in $\mathrm{Mg}$ doping concentration.

The distortion of lattice causes a small loss in their crystallinity. The $\mathrm{Mg}$ ions doping inside the crystal lattice of $\mathrm{ZnO}$ has been produced a little amount of strain in it and this results in change the regularity of crystal. The dopant materials can make changes in the lattice characteristics of the host materials. Since the ionic radius of the substituted $\mathrm{Mg}^{2+}\left(\mathrm{RMg}^{2+}=0.057\right.$ $\mathrm{nm}$ is $0.57 \AA)$ is smaller than that of $\mathrm{Zn}^{2+}\left(\mathrm{RZn}^{2+}=\right.$ $0.06 \mathrm{~nm}$ is $0.60 \AA$ ) the $\mathrm{Mg}$ ions may replace the $\mathrm{Zn}$ 
ions in the host lattice [11]. The basic structure of $\mathrm{ZnO}$ nanoparticles is found to be as their original wurtzite structure which reveals that most of the $\mathrm{Mg}^{2+}$ ions replace the $\mathrm{Zn}^{2+}$ ions.

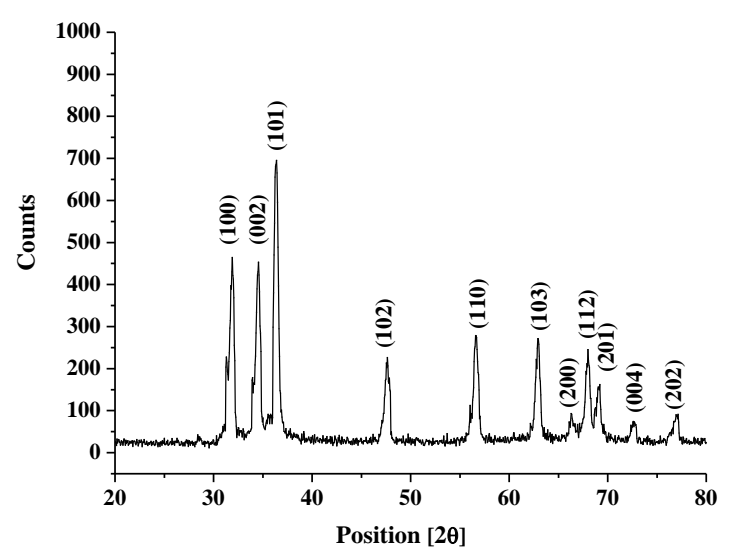

Figure 2(b): The powder X-ray diffraction pattern (XRD) patterns of the synthesized $\mathrm{Mg}$ doped $\mathrm{ZnO}$ $\left(\mathrm{Mg}_{\mathrm{x}} \mathrm{Zn}_{1-\mathrm{x}} \mathrm{O}\right.$, where $\left.\mathrm{x}=0.075 \%\right)$ nanoparticles

\subsection{Scanning Electron Microscopy of pure $\mathrm{ZnO}$ and $\mathrm{Mg}$ doped $\mathrm{ZnO}$ nanoparticles}
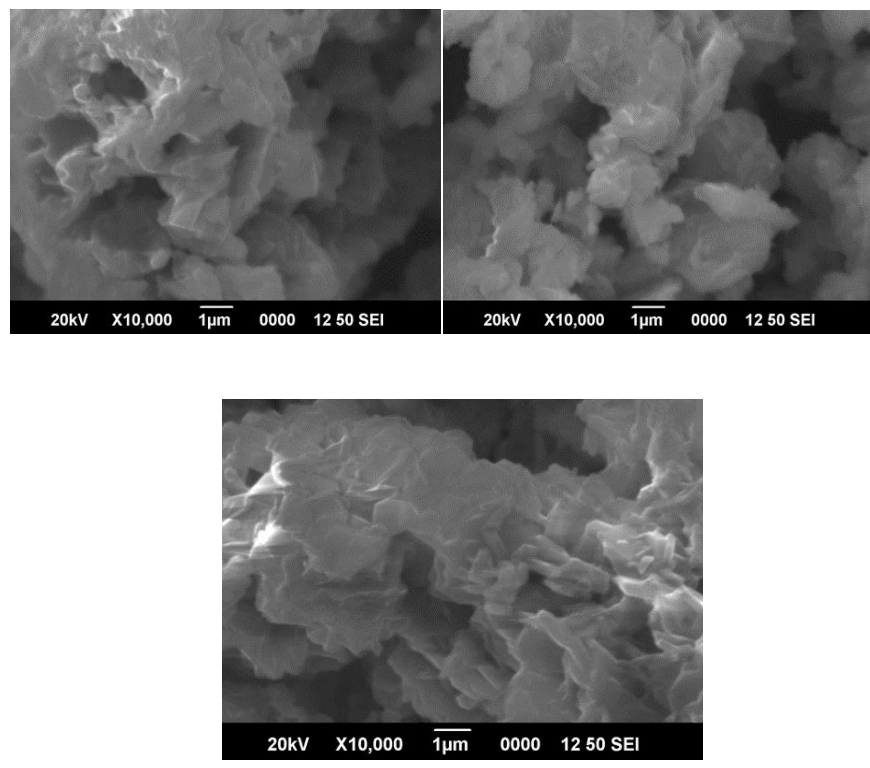

Figure 3: SEM images of $\mathrm{ZnO}$ and $\mathrm{MgxZn1-xO}(\mathrm{x}=$ $0.25 \%$, and $0.075 \%$ ) nanoparticles

The surface morphology of the prepared pure and $\mathrm{Mg}$ doped $\mathrm{ZnO}$ nanoparticles are investigated by SEM analysis shown in the figure 3 . It is observed that the particles get aggregated on their surface. Aggregation of particles on the surface has been originated from the high surface energy of the synthesized nanoparticles [12].

\subsection{UV-Visible Spectroscopy of pure $\mathrm{ZnO}$ and $\mathrm{Mg}$ doped $\mathrm{ZnO}$ nanoparticles}

The UV-Visible absorption spectra of pure and $\mathrm{Mg}$ doped $\mathrm{ZnO}$ NPs as a function of wavelength for the range of 200 to $800 \mathrm{~nm}$ are illustrated by figure 4 . From the UV- Visible spectra it is observed that the absorption peak increases with the increase in doping concentration. The increase in absorbance may be due to various factors like particle size, oxygen deficiency, and defects in grain structure [13].

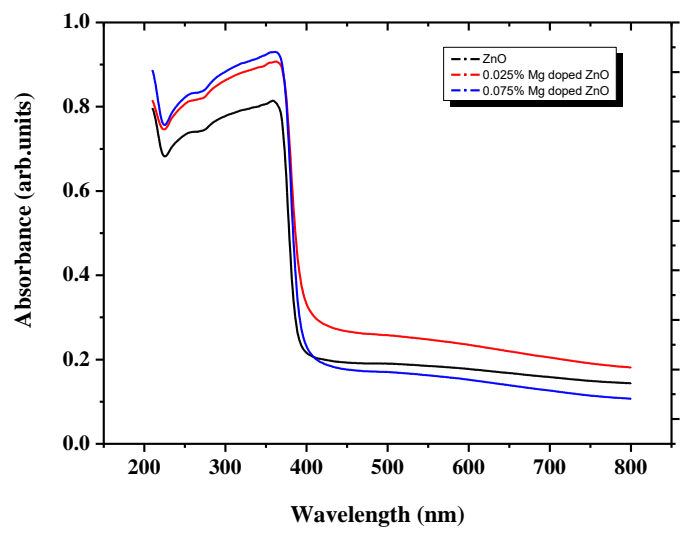

Figure 4 : UV-Visible absorbance spectra of the pure and MgxZn1-xO, ( $\mathrm{x}=0.025,0.075 \%)$ nanoparticles

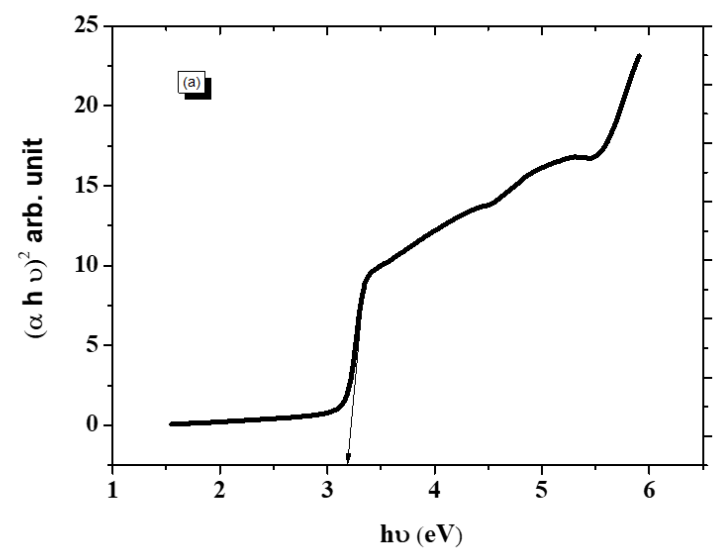

Figure 5 (a): Determination of band gap of $\mathrm{ZnO}$ nanoparticles from the plot of ( $\alpha$ hv) 2 versus photon energy (hv) in $\mathrm{eV}$ 


\section{IV.CONCLUSION}

It is to be noted that for $\mathrm{Mg}$-doped $\mathrm{ZnO}$ nanoparticles the absorption edge is shifted to the longer wavelength as increase in $\mathrm{Mg}$ content. This shifting behavior can cause a decrease in its band gap (Eg) value. The optical band gap (Eg) is determined from a Tauc-plot from the following relation (9).

$$
\alpha h v=B\left(h v-E_{g}\right)^{n}
$$

where $\alpha$ is absorption coefficient, $h$ is Plank's constant, $v$ is the frequency of light radiation, and $E_{g}$ is the band gap energy, where " $n$ " takes the value of $1 / 2$ for allowed direct transition [14]. Plots of $(\alpha h v)^{2}$ versus (hv) are made for pure and $\mathrm{Mg}$-doped $\mathrm{ZnO}$ nanoparticles. The band gap energy $\left(\mathrm{E}_{\mathrm{g}}\right)$ is obtained from the extrapolation of the linear portions of the plots onto the $\mathrm{x}$-axis.

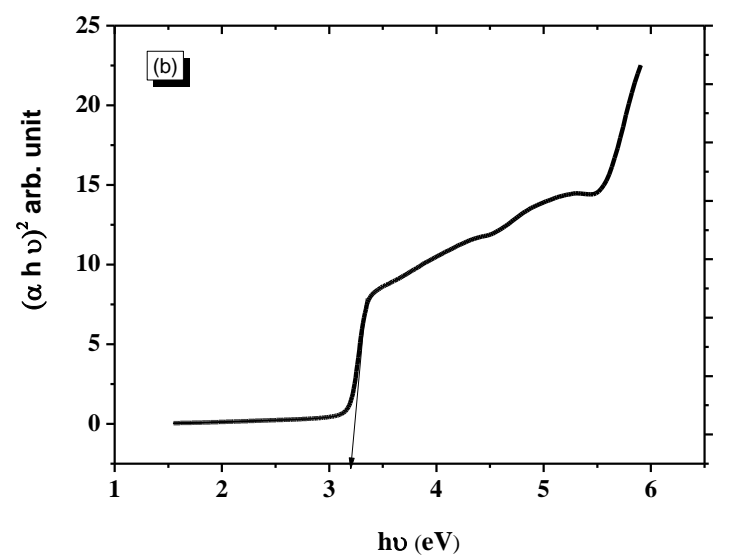

Figure 5(b): Determination of band gap of $\mathrm{Zn}_{1-\mathrm{x}} \mathrm{Mg}_{\mathrm{x}} \mathrm{O}$ (where $\mathrm{x}=0.25 \%$ and $0.075 \%$ ) nanoparticles from the plot of ( $\alpha \mathrm{hv})^{2}$ versus photon energy (hv) in $\mathrm{eV}$

From Fig.5 (a) and (b), it is found that the band gap energy $\left(E_{\mathrm{g}}\right)$ for pure $\mathrm{ZnO}$ nanoparticles is around $3.24 \mathrm{eV}$ and decreases with increase in $\mathrm{Mg}$ dopant ( 3.24 to $3.13 \mathrm{eV}$ ). The band gap is decreased due to strong quantum confinements and enhancement in their surface area to volume ratio [15]. The shifting behaviour in UV spectrum (redshift) and decrease in band gap energy $\left(E_{\mathrm{g}}\right)$ confirm the presence of $\mathrm{Mg}^{2+}$ inside the $\mathrm{Zn}^{2+}$ site of the $\mathrm{ZnO}$ lattice.
Pure and Mg-doped ZnO structures were successfully synthesized by co-precipitation method using Zinc Chloride and Sodium Hydroxide. The synthesized nanoparticles are successfully characterized by XRD, SEM, and UV-visible analysis. The XRD patterns revealed the wurtzite structure for all the nano samples. No other impurity phases were observed. The crystallite size obtained from XRD for all samples were less than $100 \mathrm{~nm}$. XRD studies confirmed that the crystallite size increases with increase in $\mathrm{Mg}$ content. Average Crystalline size of the sample calculated from Debye- Scherrer formula are 24.91 $\mathrm{nm}$ and $38.28 \mathrm{~nm}$ for the concentrations 0.025 and $0.075 \%$ of $\mathrm{Mg}$ doped $\mathrm{ZnO}$ and $16.3821 \mathrm{~nm}$ for undoped $\mathrm{ZnO}$. It is also noted that the intensity of the XRD peak decreases with increase in $\mathrm{Mg}$ doping concentration which confirms the slender loss in their crystallinity due to distortion of lattice. The surface morphology of the prepared pure and $\mathrm{Mg}$ doped $\mathrm{ZnO}$ nanoparticles are investigated by SEM analysis. The UV-Visible results revealed that the $\mathrm{Mg}$ doped $\mathrm{ZnO}$ nanoparticles the absorption edge is shifted to the longer wavelength as increase in $\mathrm{Mg}$ content. Optical band gap energy was found to decrease from 3.24 to $3.13 \mathrm{eV}$ with $\mathrm{Mg}$ doping.

\section{REFERENCES}

[1]. Wang Z. L., "Zinc oxide nanostructures: growth, properties and Applications", J. Phys. Condens. Matter, 16(2004), R829-R858.

[2]. Hahn Y. B., "Zinc oxide nanostructures and their applications", Korean J. Chem. Eng., 8(2011), 1797-1813.

[3]. Siddiqi KS, Rahman A, Tajuddin, Husen A, "Properties of zinc oxide nanoparticles and their activity against microbes. Nanoscale Res Lett 13(2008), 141.

[4]. Tripathi P, Ashraf SSZ, Naqvi AH, Azam A, Ahmed S, "Band gap engineering and enhanced 
photoluminescence of $\mathrm{Mg}$ doped $\mathrm{ZnO}$ nanoparticles synthesized by wet chemical route". J Lumin 161(2015), 275-280.

[5]. T.C.Bharat, Shubham , S.Mondal, H.S.Gupta, P.K.Singh, A.K.Das "Synthesis of Doped Zinc Oxide Nanoparticles: A Review, Materials today proceedings, 11, Part 2 (2019) , 767-775

[6]. Manaia, E.B.; Kaminski, R.C.K.; Caetano, B.L.; Briois, V.; Chiavacci, L.A.; Bourgaux, C. "Surface modified $\mathrm{Mg}$-doped $\mathrm{ZnO}$ QDs for biological imaging". Eur. J. Nanomed. 7(2015),109-120.

[7]. Yousefi, R.; Zak, A.K.; Jamali-Sheini, F. Growth, $\mathrm{X}$-ray peak broadening studies, and optical properties of $\mathrm{Mg}$-doped $\mathrm{ZnO}$ nanoparticles. Mater. Sci. Semicon Proc. (16)2013, 771-777.

[8]. Jiang, Z.Y.; Zhu, K.R.; Lin, Z.Q.; Jin, S.W.; Li, G. "Structure and Raman scattering of Mg-doped $\mathrm{ZnO}$ nanoparticles prepared by sol-gel method". Rare Met. 37(2018), 881-885.

[9]. Fujihara, S.; Ogawa, Y.; Kasai, A. "Tunable Visible Photoluminescence from $\mathrm{ZnO}$ Thin Films through Mg-Doping and Annealing", ACS Chem. Mater. (16)2004,2965-2968.

[10]. Singh, J.; Kumar, P.; Hui, K.S.; Hui, K.N.; Ramam, K.; Tiwari, R.S.; Srivastava, O.N. "Synthesis, band-gap tuning, structural and optical investigations of $\mathrm{Mg}$ doped $\mathrm{ZnO}$ nanowires". RSC CrystEngComm, 14( 2012), 5898-5904.

[11]. Boggs S (2009) Petrology of Sedimentary Rocks. 2nd edition, University of Oregon, Cambridge University Press.

[12]. He Q, Zhong C, Wu JW, "Magnetic iron oxide nanoparticles: synthesis and surface functionalization strategies". Nanoscale Res Lett 3(2008), 397-415.

[13]. Mir FA, Batoo, "KM Effect of $\mathrm{Ni}$ and $\mathrm{Au}$ ion irradiations on structural and optical properties of nanocrystalline Sb-doped $\mathrm{SnO} 2$ thin films". Appl Phys A 122(2016), 418.
[14]. Kaur P, Kumar S, Negi NS, Rao SM "Enhanced magnetism in Cr-doped $\mathrm{ZnO}$ nanoparticles with nitrogen co-doping synthesized using sol-gel technique”. Appl Nanosci 5(2015), 367-372.

[15]. Khajuri S, Sanotra S, Lado J, Sheikh HN, "Synthesis, characterization and optical properties of cobalt and lanthanide doped CdS nanoparticles". J Mater Sci Mater Electron 26(2015), 7073-7080.

\section{Cite this article as :}

Roxy M S, Ananthu A, Sumithranand V B, "Synthesis and Characterization of Undoped and Magnesium Doped Zinc Oxide Nanoparticles ", International Journal of Scientific Research in Science, Engineering and Technology (IJSRSET), Online ISSN : 2394-4099, Print ISSN : 2395-1990, Volume 8 Issue 2, pp. 134-139, March-April 2021. Available at doi : https://doi.org/10.32628/IJSRSET218225 Journal URL : https://ijsrset.com/IJSRSET218225 